\title{
Protein Complexity of Central Nervous System Cell Lines
}

\author{
David Schubert, Barry Brass, and Jean-Pierre Dumas \\ The Salk Institute for Biological Studies, San Diego, California 92138-9216
}

\begin{abstract}
The total extracellular proteins and the most abundant 960 intracellular proteins of clonal CNS nerve and glial cell lines were examined by quantitative 2-dimensional acrylamide gel electrophoresis. While less than $0.2 \%$ of the intracellular proteins differ among the 5 nerve and 4 glial cell lines studied, over $65 \%$ of the extracellular proteins vary in distribution between the 2 major classes of CNS cells. These data indicate that the phenotypic complexity of nerve and glia populations is similar and that most of the protein complexity is in extracellular molecules.
\end{abstract}

It has been argued on the hasis of RNA hybridization studies that the mammalian CNS has a severalfold higher number of unique mRNA sequences than other tissues (Brown and Church, 1972; Chikaraishi et al., 1983; Hahn and Laird, 1971). Assuming that these mRNAs are translated, there are 2 alternatives that could explain the apparent increase in protein complexity within the brain; they are not mutually exclusive. Each cell within the CNS might make many more species of proteins than cells of other tissues, or there might be a greater number of cell types, each making a few unique species that contribute to total tissue complexity but whose overall protein complexity is similar to cells of different tissues. To distinguish between these alternatives, protein synthesis in a series of clonal CNS nerve and glial cell lines was examined by 2 -dimensional gel electrophoresis. Total cellular protein synthesis and the extracellular proteins released into the culture medium were analyzed by computer-assisted methods. It is shown that there is a great deal of variability in the protein species synthesized by cells from the rat CNS and that the variability within the glial population is as great as that between the nerve cells. The majority of this protein complexity is associated with the extracellular proteins, which are more abundant in nerve and glia than in mesodermally derived cells. The total number of cellular proteins synthesized by clonal CNS cell lincs is, however, indistinguishable from that of mesodermal cells. It follows that the higher protein complexity in the CNS is due to both the large number of unique phenotypes and the increased number of extracellular proteins relative to other tissues.

\section{Materials and Methods}

\section{Cell lines}

A list of the cell lines used in the following experiments is given in Table 1 along with some of the properties on which the assignment to the nerve, glial, or mesodermal classes was made. The nerve and glial cells were cloned from nitrosoethylurea-induced brain tumors (Schubert et al., 1974). The major criterion on which the classification of the nerve

\footnotetext{
Received Oct. 22, 1985; revised Mar. 18, 1986; accepted Apr. 4, 1986.

This work was supported by grants from the Muscular Dystrophy Association of America and the National Institutes of Health. We wish to thank J. H. Steinbach, S. Halegoua, B. Stallcup, F. Crick, P. Maher, J. Garrels, D. Chikaraishi, and M. LaCorbiere for their helpful comments on the manuscript, and Nancy Goodknight for its preparation.

Correspondence should be addressed to David Schubert, The Salk Institute for Biological Studies, P.O. Box 85800, San Dicgo, CA 92138-9216.

Copyright (C) 1986 Society for Neuroscience $0270-6474 / 86 / 102829-08 \$ 02.00 / 0$
}

and glial cells was made was electrical excitability, but a large number of other markers, such as cell-surface antigens, are in agreement with the physiology. Nile and $\mathrm{Nl}$ are nerve-specific antigens (Richter-Landsberg et al., 1984; Stallcup, 1981; Stallcup et al., 1983), and G2 is found only on some glial cells (Stallcup and Cohn, 1976). The clonal mesodermal cell lines were derived from both normal embryonic and neoplastic cells. 3Y 1 and A10 were isolated from embryonic skin and aorta smooth muscle, respectively (Kimes and Brandt, 1976). L6 was derived from neonatal skeletal muscle (Yaffe, 1968), while B44 was isolated from a rat brain tumor (Schubert et al., 1974). CH5 was cloned from rat cartilage (Nevo and Dorfman, 1972) and SC from a rat chondrosarcoma (Mason et al., 1982). All cell lines were cultured as described in the original manuscripts.

\section{Two-dimensional acrylamide gel electrophoresis}

To assay extracellular proteins, cells were labeled in serum free modified Eagle's medium for $18 \mathrm{hr}$ with ${ }^{35} \mathrm{~S}$-methionine $(200 \mu \mathrm{Ci} / \mathrm{ml})$. The absence of serum for short-term biosynthetic labeling of cells previously grown in serum does not significantly alter the pattern of released extracellular proteins (Truding et al., 1975). The supernatants were filtered through G25 to remove free isotope and salts, and lyophilized. Small peptides would also be removed at this step. The proteins released into the culture medium were assayed by 2-dimensional acrylamide gel electrophoresis according to the method of O'Farrell (1975) as modified by Garrels (1979). The first dimension contained $\mathrm{pH} 3-10$ ampholytes; the higher $\mathrm{pH}$ is on the right. The second-dimension slabs contained $7.5 \%$ acrylamide and $0.1 \%$ SDS.

To prepare 2-dimensional acrylamide gel maps of total cellular proteins, exponentially dividing cells were labeled with ${ }^{35} \mathrm{~S}$-methionine $(200$ $\mu \mathrm{Ci} / \mathrm{ml}$ ) for $2 \mathrm{hr}$ in modified Eagle's medium minus methionine but containing $10 \%$ of the original growth medium, including serum. The cells were harvested and electrophoresed on 2-dimensional gels as described for extracellular proteins. The amount of isotope loaded onto each gel is described in the figure legends.

Radioautographs of the acrylamide gels were scanned on a drum scanner and analyzed using computer programs similar to those produced by Garrels (Garrels, 1979; Garrels et al., 1984). Pairwise matching of proteins was done on the basis of computer-generated synthetic images of the gel patterns as described in the text.

\section{Results}

\section{Extracellular proteins}

Proteins that are released into the medium of cultured cells are derived either via a direct export process (secretion) or by "shedding" from the cell surfaces (Doljanski and Kapellar, 1976; McCormick et al., 1979; Schubert, 1976). The latter group is therefore a reflection of the cell's external plasma membrane composition. To examine the synthesis of these extracellular proteins, exponentially dividing cells were labeled with ${ }^{35} \mathrm{~S}$-methionine for $18 \mathrm{hr}$, and the total protein released into serumfree medium was examined by 2 -dimensional (2D) acrylamide gel electrophoresis. Proteins released from individual cell lines were initially separated on $\mathrm{pH} 3-10$ isoelectric focusing gels, followed by electrophoresis in slab gels containing $7.5 \%$ acrylamide and $0.1 \%$ SDS. This gel system resolves proteins within the isoelectric focusing range and with molecular weights greater than $30,000 \mathrm{Da}$. Less than $5 \%$ of the extracellular proteins fell 


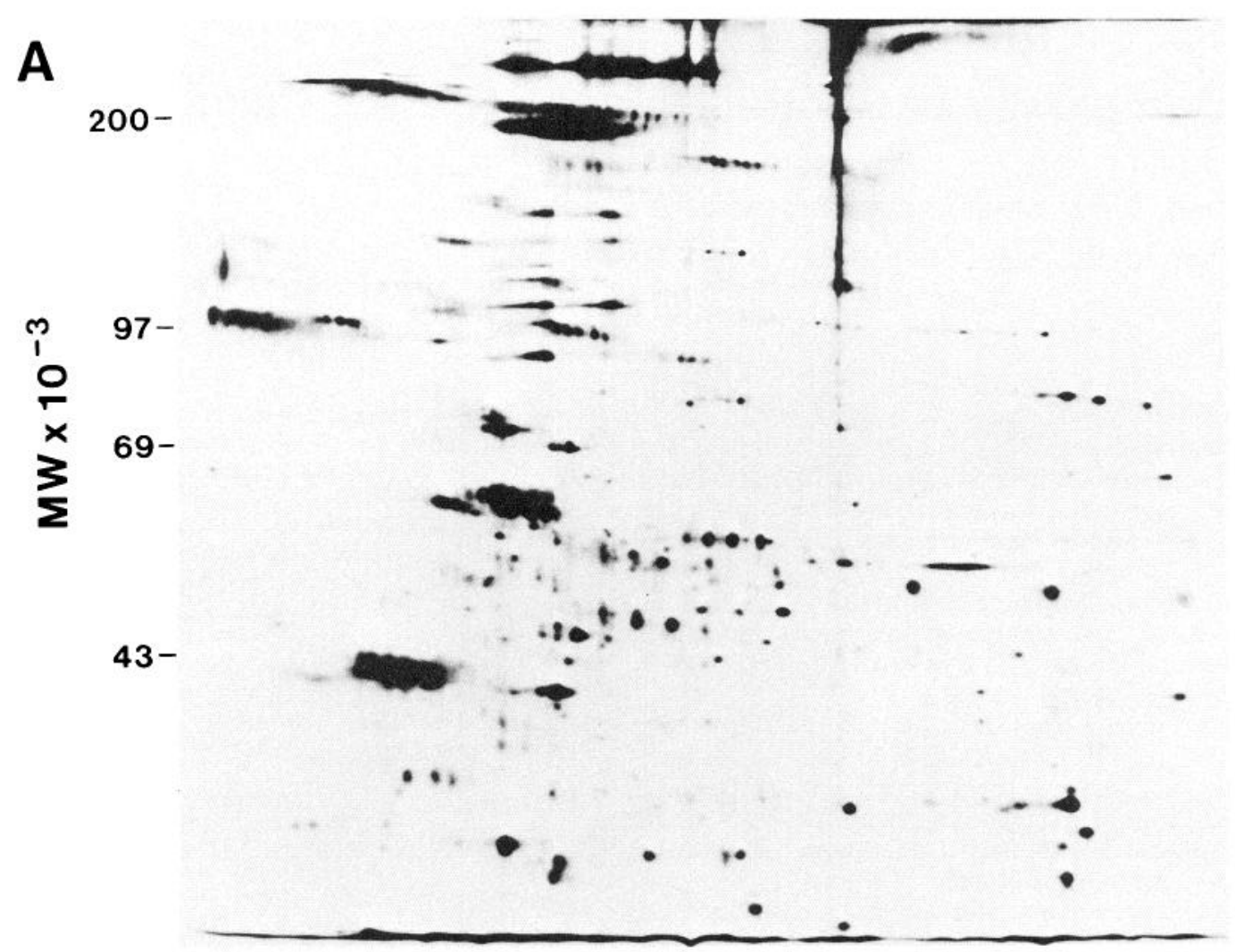

B

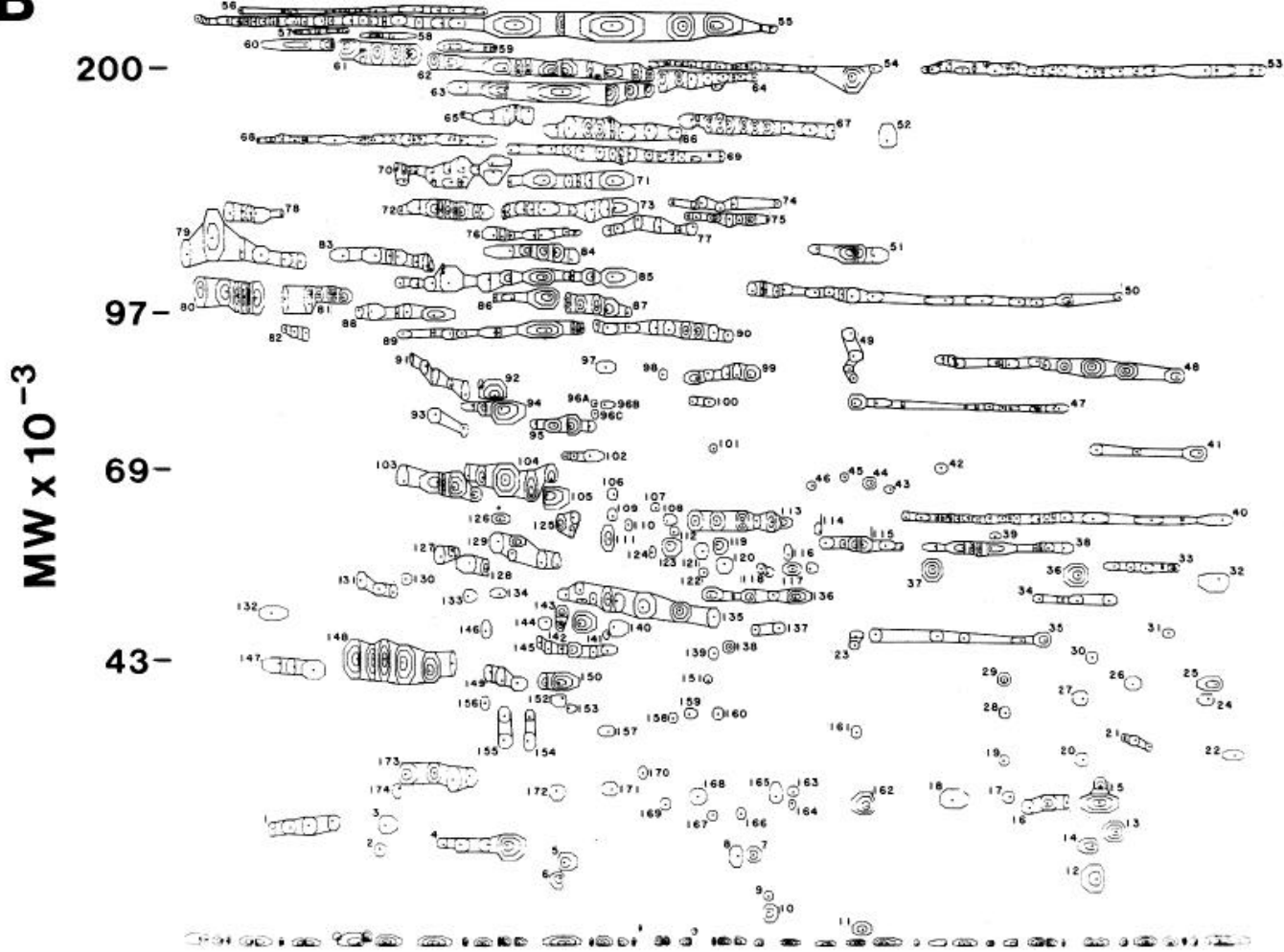

Figure 1. Separation of extracellular proteins from nerve and glia. Five exponentially dividing nerve and 4 glial lines were labeled and the proteins released into the culture supernatant isolated as described in Materials and Methods. ${ }^{35} \mathrm{~S}$-methionine, $100,000 \mathrm{cpm}$, was loaded onto $7.5 \%$ acrylamide gels, and following electrophoresis, the ${ }^{3} \mathrm{H}$-enhanced (New England Nuclear) gels were exposed to film for $10 \mathrm{~d}\left(1 \times 10^{6} \mathrm{dpm} \mathrm{d}\right)$. The original fluorogram of the nerve-glia extracellular proteins is shown in $A$, and a synthetic image generated from a computer analysis of the gel in $B$. Each spot on the gel is represented by a polygon encircling a point at the center of the spot. The size of the polygon and the number of "contour" lines within it are proportional to the optical density of the spot on the fluorogram. The computer keeps track of the spot position and intensity. Spots 
Table 1. Cell lines

\begin{tabular}{|c|c|c|c|c|c|c|}
\hline \multirow[b]{2}{*}{ Cell line } & \multirow{2}{*}{$\begin{array}{l}\text { Electrical } \\
\text { excitability }\end{array}$} & \multirow{2}{*}{$\begin{array}{l}\text { Sodium } \\
\text { flux }\end{array}$} & \multicolumn{3}{|c|}{ Surface antigens } & \multirow[b]{2}{*}{ Cell type } \\
\hline & & & NILE & N1 & G2 & \\
\hline B35 & + & + & + & + & - & Nerve \\
\hline B50 & + & + & + & + & - & Nerve \\
\hline B65 & + & - & + & + & - & Nerve \\
\hline $\mathrm{B} 103$ & + & + & + & + & - & Nerve \\
\hline B104 & + & + & N.D. & + & - & Nerve \\
\hline $\mathrm{B} 12$ & - & - & N.D. & N.D. & N.D. & Glia \\
\hline $\mathrm{B} 23$ & - & - & - & - & - & Glia \\
\hline $\mathrm{B} 28$ & - & - & - & - & + & Glia \\
\hline B92 & - & - & - & - & + & Glia \\
\hline L6 & + & + & - & - & - & Skeletal muscle \\
\hline B44 & + & + & - & - & - & Skeletal muscle \\
\hline A 10 & + & + & N.D. & N.D. & N.D. & Smooth muscle \\
\hline $3 \mathrm{Y} 1$ & - & - & N.D. & N.D. & N.D. & Fibroblast \\
\hline CH5 & - & - & N.D. & N.D. & N.D. & Chondrocyte \\
\hline $\mathrm{SC}$ & - & - & N.D. & N.D. & N.D. & Chondrocyte \\
\hline
\end{tabular}

Electrical excitability was assayed by intracellular recording and sodium flux by veratridine stimulated uptake of ${ }^{22} \mathrm{Na}^{+}$. N.D., not determined.

below this minimum molecular weight (see also Duncan and McConkey, 1982). Fluorograms of the separated proteins from each cell line were compared pairwise with each other and with a mixture of proteins from all of the cell lines. Figure $1 A$ shows the radioautographic image of a composite gel in which the extracellular proteins of 5 clonal nerve cell lines and 4 clonal glial cell lines were mixed prior to gel analysis. This gel serves as a master against which the relative distribution of proteins in the clonal cell lines and primary cultures can be compared. For quantitation and facilitation in handling the data, the radioautographs of the 2D gels were scanned and analyzed by computer to obtain the relative amounts of isotope in each protein spot on the gel (Garrels, 1979; Garrels et al., 1984). Figure $1 B$ shows the computer-generated synthetic image of the gel above it; the spots are numbered for bookkeeping purposes and for the sake of discussion. When extracellular glycosylated proteins are separated on the basis of isoelectric point, as is done in the first dimension of $2 \mathrm{D}$ gels, single proteins are frequently resolved into a series of spots due to their charge heterogeneity. For the purpose of this article, the multiple spots with similar molecular weights which were considered as one polypeptide are circumscribed in Figure $1 B$. These assignments were made on the basis of covariation of the encircled spots on a large number of gels. Continued exposure of the film past $1 \times 10^{6}$ $\mathrm{dpm} d$ revealed a faint background of proteins that resembled those from total cells. The appearance of these proteins was most likely due to the lysis of a few cells during the isotopic labeling protocol. Two-dimensional gel profiles of extracellular proteins from the clonal C6 glial line have been published that are very similar to those presented here (Arenander and De Vellis, 1981).

The distribution of the extracellular proteins among 9 clonal nerve and glial cell lines is summarized in Table 2. The data are obtained by pairwise matching of the total proteins from the cells in the left-hand column with those from the cells at the top. The total number of proteins released by cells of each line is in parentheses. The data are presented as the percentage of the total proteins shared between pairs of cells (number of the proteins present in the cells listed at the left that are also present in the cells at the top, divided by the number of proteins in the cells at the top, multiplied by 100). For example, all of the proteins present in B35 growth conditioned medium (118 proteins) are also present in B28 medium ( 164 proteins), while only $71 \%$ of the proteins found in B28 growth conditioned medium are also found in B35 medium. In addition, of the 172 resolved proteins secreted by the cell lines, only $63(35 \%)$ are found in the supernatants of all of the individual cell lines; the remaining $65 \%$ vary in distribution between the nerve and glial clones. It was expected that there would be groups of proteins that are found only in glia or only in nerve. However, only protein 2 (Fig. $1 B$ ) is uniquely associated with nerve cells-none was found in the 4 glial lines or in primary glial cultures. No protein was found to be present only in glial cells. Each cell had at least one unique extracellular protein. These data show that there is a great deal of complexity among the extracellular proteins of nerve and glial cells and that the variability among the glial cells is as great as that between the nerve cells.

One of the putative glial cell lines, B28, has the unique property of releasing all except a few of the proteins that are found in the sum total of the other 8 cell lines (Table 2). Extracellular proteins of 3 independently isolated clones of the B28 tumor were examined by 2D acrylamide gel electrophoresis, and all had identical patterns of proteins. Therefore, B28 synthesizes the extracellular proteins released by both CNS nerve and glial cell lines. B28 has a near diploid karyotype, ruling out the possibility that it arose via the fusion of a nerve and glial cell (unpublished observations). Since it is unlikely that a cell could sequentially acquire the ability to make a "complete" set of extracellular proteins, it is possible that B28 is a precursor to both CNS nerve and glia and that the ability to synthesize spe-

that were reproducibly streaked out along the first dimension, probably due to heterogeneous glycosylation, were connected by a continuous line and were considered as one polypeptide for the purpose of this study. Each gel was exposed for $1 \times 10^{6}$ and $3 \times 10^{6} \mathrm{dpm} \mathrm{d}$. The lower exposure was used for assaying the presence or absence of a spot, and a spot was considered missing if it was not detectable at the longer exposure. In addition, each cell type was labeled at least 3 times and gels were run from each sample. 


\begin{tabular}{lcccccccccc}
\hline Table 2. & \multicolumn{10}{c}{ Ratio of shared extracellular proteins in nerve and glia } \\
\multicolumn{1}{c}{} & B35 & B50 & B65 & B103 & B104 & B12 & B23 & B28 & B92 & PG \\
Cell line & $(118)$ & $(143)$ & $(132)$ & $(118)$ & $(131)$ & $(139)$ & $(131)$ & $(164)$ & $(115)$ & $(65)$ \\
\hline B35 & 100 & 77 & 80 & 83 & 81 & 77 & 78 & 71 & 80 & 77 \\
B50 & 94 & 100 & 92 & 93 & 94 & 89 & 88 & 85 & 90 & 81 \\
B65 & 90 & 85 & 100 & 91 & 97 & 82 & 82 & 80 & 83 & 74 \\
B103 & 84 & 77 & 82 & 100 & 79 & 74 & 79 & 71 & 77 & 83 \\
B104 & 89 & 86 & 86 & 87 & 100 & 82 & 81 & 79 & 81 & 80 \\
B12 & 91 & 86 & 86 & 87 & 87 & 100 & 88 & 82 & 91 & 78 \\
B23 & 87 & 81 & 82 & 88 & 81 & 84 & 100 & 77 & 95 & 91 \\
B28 & 100 & 98 & 98 & 100 & 100 & 98 & 98 & 100 & 96 & 94 \\
B92 & 77 & 73 & 72 & 76 & 72 & 75 & 75 & 68 & 100 & 82 \\
PG & 42 & 40 & 37 & 46 & 40 & 37 & 45 & 40 & 49 & 100
\end{tabular}

The protein content of complete growth conditioned medium was resolved on $2 \mathrm{D}$ acrylamide gels and the proteins of the various cell lines matched pairwise against each other. The data are based on film exposures of $1 \times 10^{6} \mathrm{dpm} d$ (for example, 100,000 dpm per gel exposed $10 \mathrm{~d}$ ). At least 3 gels were run for each cell line from independent labelings. Multiple exposures were made as described in Fig. 1 and Materials and Methods, and the absence of a protein at $1 \times$ $10^{6} \mathrm{dpm} d$ was verified against longer exposures. The data are presented as the percentage (ratio $\times 100$ ) of the extracellular proteins that are common to the cells on the left and the cells at the top compared to total number of proteins in the cells at the top. The numbers in parentheses in the top row are the total number of proteins detected in that cell's growth conditioned medium. PG, primary glial cells from 4-d-old rat cerebellum after 2 weeks in culture. Of the 172 extracellular proteins, 63 were present in all 9 cell lines, 30 in 8 cell lines, 24 in 7,13 in 6,10 in 5,12 in 4,8 in 3,5 in 2 , and 4 in 1 cell line.

cific proteins is sequentially lost as the cell further differentiates. For example, the loss of ion channels as cells mature has frequently been documented (see, for example, Hagiwara and Miyazaki, 1977; Spitzer, 1979), and individual CNS cells have been described that share traits of both nerve and glia (DeVitry et al., 1980; Schubert et al., 1974; Tomozawa and Sueoka, 1978; Wilson et al., 1981).

To rule out the possibility that the extracellular proteins released by the clonal cell lines were generated as a result of their adaptation to culture, these proteins were compared with the extracellular material of cells cultured from 4-d-old rat cerebellum. These cultures were greater than $90 \%$ glial as defined by staining with anti-glial fibrillary acidic protein. Table 2 shows that all except $4(94 \%)$ of the extracellular proteins present in the primary cultures are also present in the B28 glial-like cell, which contains over $96 \%$ of the proteins found in the combined nerve and glial cell lines.

\section{Cellular proteins}

In contrast to the extracellular proteins, the variability among the CNS cell lines with respect to total cellular proteins is quite limited. Figure 2 shows the $2 \mathrm{D}$ gel of a clonal nerve cell line,

Table 3. Ratios of shared extracellular proteins in mesodermal cells

\begin{tabular}{lrrrrrr}
$\begin{array}{l}\text { Cell } \\
\text { line }\end{array}$ & $\begin{array}{l}\text { L6 } \\
(50)\end{array}$ & $\begin{array}{r}\text { B44 } \\
(43)\end{array}$ & $\begin{array}{l}\text { A10 } \\
(48)\end{array}$ & $\begin{array}{l}\text { CH5 } \\
(39)\end{array}$ & $\begin{array}{l}\text { 3Y1 } \\
(48)\end{array}$ & $\begin{array}{l}\text { SC } \\
(41)\end{array}$ \\
\hline L6 & 100 & 98 & 92 & 92 & 90 & 93 \\
B44 & 84 & 100 & 81 & 82 & 90 & 87 \\
A10 & 88 & 91 & 100 & 90 & 96 & 93 \\
CH5 & 76 & 75 & 73 & 100 & 78 & 95 \\
3Y1 & 86 & 96 & 96 & 95 & 100 & 92 \\
SC & 78 & 81 & 75 & 97 & 82 & 100
\end{tabular}

The extracellular proteins of 6 clonal mesodermal cell lines were electrophoresed on 2D gels and the protein spots matched pairwise as described for the nerve and glial proteins in Table 2 . Gel exposures of $1 \times 10^{6} \mathrm{dpm} d$ were used. The data are expressed as the percentage (ratio $\times 100$ ) of the proteins shared by the paired cells in the matrix that are present in the cell line in the top row. The numbers in parentheses are the total number of proteins detected in the growth conditioned medium of that cell line.
B35. The positions of the 16 proteins that are variable between the 9 nerve and glia are drawn into this profile. Of the 960 proteins reproducibly resolved by these gels at an exposure of $3 \times 10^{6} \mathrm{dpm} \mathrm{d}, 944$ were common to all of the cell lines. With 1 exception, protein 16 , the remaining unshared proteins were apparently randomly distributed throughout the nerve and glial cell lines. With the exception of B28, each cell line had one or more unique proteins. Protein 16 was found in all of the nerve cell lines but in none of the glial cells except B28. As with the extracellular proteins, B28 had the most proteins in common with all of the cells. Only 5 proteins of the 960 were not found in B28; none was found in B28 that was not present in any other cell line.

\section{Mesodermal cells}

The above data show that there is a great deal of protein variability between the extracellular proteins of CNS nerve and glial cells, while there are few differences among total cellular proteins. To ascertain if the protein variability among clonal neuroectodermally derived cell lines is greater than that between a similar set of cells from a different germ layer, the extracellular and total cellular proteins were assayed in a collection of 6 clonal cell lines from differentiated rat mesodermal tissues. These include skeletal muscle myoblasts, smooth muscle myoblasts, fibroblasts, and chondrocytes. Table 3 shows that although the differences in the distribution of shared proteins between pairs of CNS cclls $(82 \pm 10)$ and pairs of mcsodcrmal cells $(88 \pm 7)$ is not great, the absolute number of protein differences within the mesodermal population is much smaller than for the CNS cells. This is because the number of extracellular proteins from the mesodermal cells is smaller-about one-third that of neuroectoderm.

In contrast to the more limited variation in the extracellular proteins of mesodermal cells relative to CNS cells, the differences in cytoplasmic protein composition is similar between the 2 groups of cells. Figure 3 shows the proteins of A10, a smooth muscle cell line. Circled and numbered are the positions of the 16 proteins whose presence varies among the 6 mesodermal cell lines examined. This number of variable proteins was similar to that of the CNS cells.

A direct comparison between the sum total of the CNS cellular 


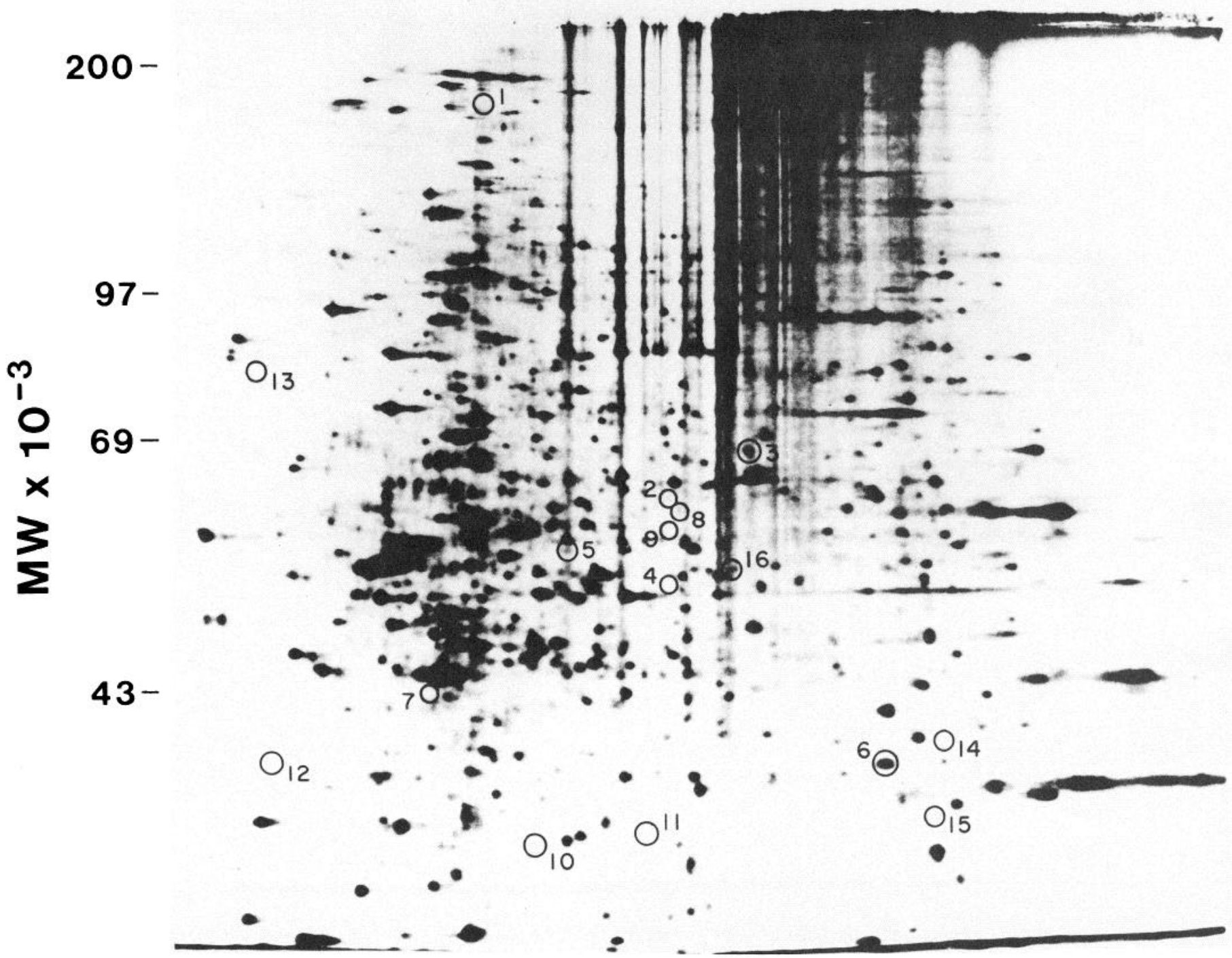

Figure 2. Cellular proteins of nerve and glia. Exponentially dividing nerve (5) and glial (4) cells were labeled with ${ }^{35}$ S-methionine for 2 hr as described in Materials and Methods, with 200,000 dpm applied to gels and the gels exposed to film for 5, 15 , and $30 \mathrm{~d} .3 \times 10^{6} \mathrm{dpm}$ d is shown in this figure. The original data for the B35 nerve cell line are shown, and the position of proteins that were present in the other 4 nerve and 4 glia or that varied between them are indicated by the numbered circles. The presence or absence of the protein was checked by comparing longer exposures with the $3 \times 10^{6} \mathrm{dpm}$ d exposure used to standardize the data. Each cell line was labeled independently and gels run at least 3 times to assure the reproducibility of each circled protein.

proteins in Figure 2 and the total mesodermal proteins in Figure 3 indicates that of the reproducibly resolved proteins, only $73 \%$ are shared; $15 \%$ of the proteins present in mesoderm are not found in the CNS cells; and $12 \%$ present in CNS are not found in mesoderm. None of the 16 variable proteins within each group is shared. When the combined extracellular proteins from the mesodermal cells are matched with those from the nerve and glia, less than $30 \%$ of the CNS proteins are also present in mesoderm.

It is possible to obtain an estimate of the number of proteins in neuroectodermal cells relative to mesodermal cells by isotopically labeling clonal cell lines of each cell type, loading identical amounts of radioactivity on the gels, and counting the protein spots on the radioautograms at different exposures. The number of proteins that were scored either by the computer or by eye were essentially identical between mesodermal and neuronal cells. As indicated above, both neuroectodermal and mesodermal cells produced about 970 protein spots at an exposure of $3 \times 10^{6} \mathrm{dpm} \mathrm{d}$. An exposure of $1 \times 10^{7} \mathrm{dpm} \mathrm{d}$ generated approximately 1500 spots in both cell types, but quantitative computer analysis of the gels was impossible because of the spot density. However, a careful visual comparison of the gels revealed no differences in spot number at this high film exposure. These data show that the number of proteins synthesized by neuroectoderm and mesoderm is essentially the same.

As a control for the effect of transformation on the synthesis of extracellular proteins, proteins from 2 pairs of clonal cell lines with similar phenotypes but different tumorigenicities were examined. L6 is a nontumorigenic rat skeletal muscle myoblast cell line (Schubert and LaCorbiere, 1980; Yaffe, 1968), while B44 is a skeletal muscle myoblast line derived from a rat tumor (Schubert et al., 1974). Both cell lines divide as mononucleate myoblasts and at confluency fuse to form multinucleate, striated myotubes. $\mathrm{CH} 5$ and SC lines are derived from normal cartilage and a chondrosarcoma, respectively (Mason et al., 1982). The myoblast total extracellular proteins are similar (Table 3), and there was only 1 qualitative difference among the intracellular proteins. A similar result was obtained with the chondrocyte 


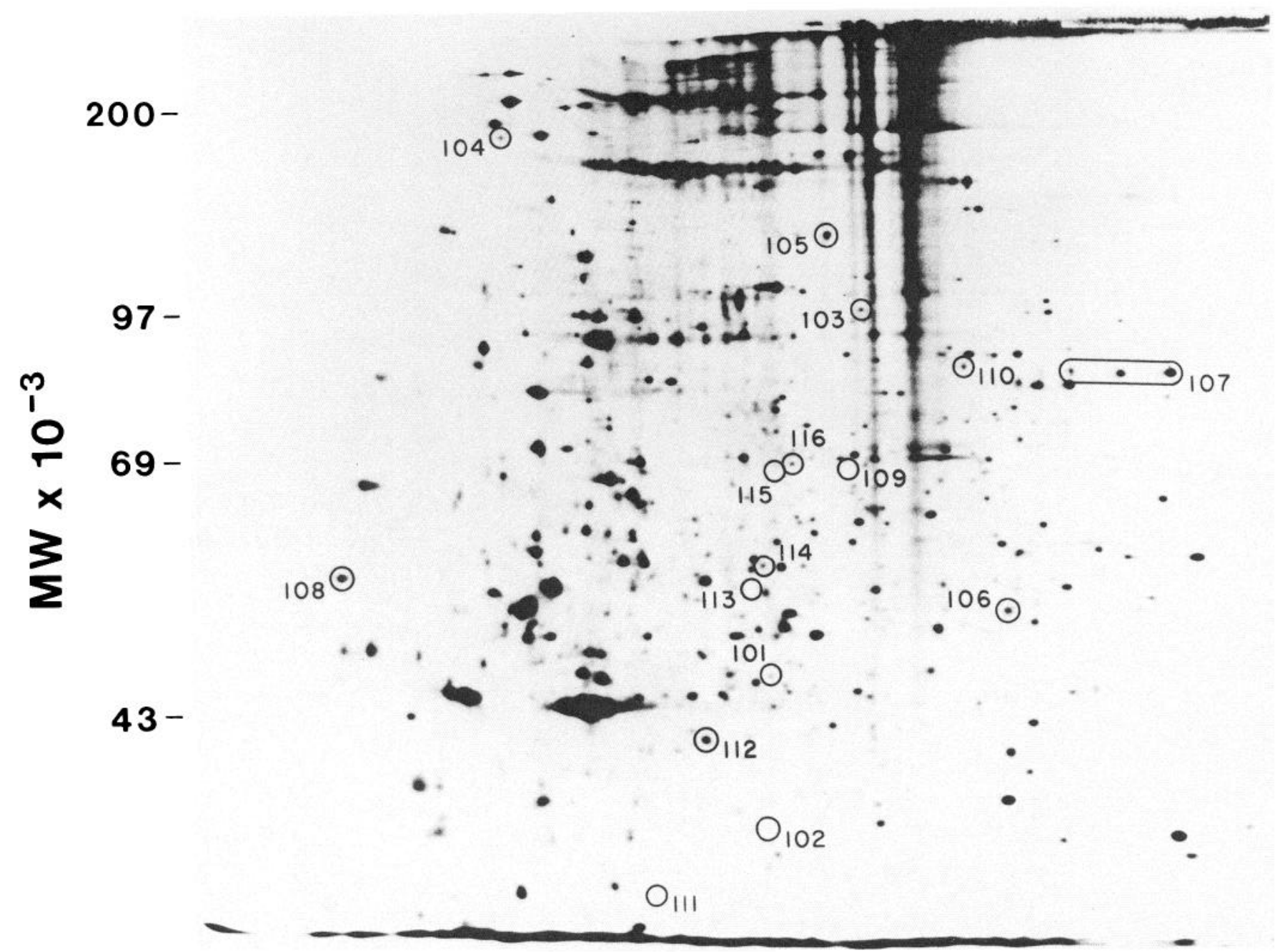

Figure 3. Cellular proteins of mesodermal cells. Exponentially dividing clones of L6, A10, B44, CH5, and 3Y1 were labeled with ${ }^{35}$ S-methionine as described in Figure 2, with $200,000 \mathrm{dpm}$ applied to the gels and the enhanced gels exposed to film for 5, 15, and $30 \mathrm{~d}$. In this figure the $5 \mathrm{~d}$ exposure $\left(1 \times 10^{6} \mathrm{dpm}\right.$ d) of A10 is shown. A pairwise comparison of the five cell lines generated 16 proteins that varied between the cells. These proteins or their positions are indicated by numbered circles. As with the neuronal cells, each mesodermal cell line was labeled at least 3 times.

pair. These results show that transformation does not necessarily lead to a high variability in protein synthesis. In addition to the rat cell lines, the extracellular and total cellular proteins of uncloned human skin fibroblasts from 12 individuals have been studied by the techniques described above. Of the 40 proteins secreted by each of the 12 cell lines, only a single difference was detected, and of the 1000 intracellular proteins assayed in each cell line, only 2 differences were detected (unpublished observations). It is probable that these are examples of polymorphisms in the human population.

\section{Discussion}

The above data show that the complexity of proteins in CNS nerve and glial cells is very similar and that most of the protein variability is among the extracellular proteins. An analysis of this type has, however, 2 potential sources of errors-the resolution of the gel system and the phenotype of the cells. Twodimensional gel electrophoresis of cellular proteins should present a reasonable estimate of the number of proteins synthesized by cells. There are, however, some technical limitations to the maximum number of proteins that can be detected by the conditions employed there. There are 3 problems with respect to resolution: (1) some proteins, such as hydrophobic membrane components, may be insoluble; (2) very basic proteins are not retained by the focusing gel; (3) proteins of less than 30,000 MW are not resolved in the second dimension, although their presence is detectable at the buffer front. It has been estimated that between 20 and $30 \%$ of the total cellular proteins could be lost due to these difficulties (Duncan and McConkey, 1982; Garrels, 1979; and unpublished observations). Because very few proteins with charge heterogeneity are seen in gels of total cellular protein, it is likely that intrinsic membrane proteins are not resolved because of solubility problems. Some of these proteins are, however, shed from the cell surface and represented among the more hydrophilic extracellular proteins (Doljanski and Kapellar, 1976; Schubert, 1976). Since there are very few basic extracellular proteins (J. Garrels and D. Schubert, unpublished observations), the loss of this class of proteins should not significantly change the results. Finally, electrophoresis of both total and extracellular proteins on $12 \%$ acrylamide gels only resolved a few additional low-molecular-weight proteins. Unless all of the protein complexity is associated with the unresolved subset of intracellular proteins, the above limitations fail to alter the conclusion that the major source of availability among CNS cells is in extracellular proteins.

With respect to the sensitivity of the method, it has been shown that between 10,000 and 20,000 poly(A)-containing unique mRNA sequences occur on the polysomes of most tis- 
sues, with a total number of 200,000-800,000 mRNAs per cell (Axel et al., 1976; Cobert et al., 1977; Hastie and Bishop, 1976); 10-fold higher estimates for different mRNAs have been obtained for the brain (Chikaraishi et al., 1983). On the basis of hybridization kinetics, it has been suggested that most of the mRNA species make up a rare or "complex" class of mRNA molecules which are represented at between 1 and 10 copies per cell (see, for example, Axel et al., 1976). Copy numbers of less than 1 unique RNA per cell have been obtained for mRNAs from the nervous system (Beckmann et al., 1981). On the basis of sample load and the ability to detect a spot containing $2 \mathrm{dpm}$ in a 1 week exposure (Laskey and Mills, 1975), it has been established that the methods used here can detect a protein representing $0.0003 \%$ of the total cellular proteins (Duncan and McConkey, 1982; Garrels, 1979; O'Farrell, 1975). Proteins translated at an average frequency from 1 mRNA molecule per cell could therefore be detected by our 2D gel system. mRNA species with a frequency of less than 1 per cell may not be detected. These very rare ( $<1 \mathrm{mRNA}$ per cell) transcripts may make up a major portion of the unique sequences within the nervous system, for polysomal RNAs from 2 of the cell lines used in our experiments have copy numbers of less than 1 per cell (Beckmann et al., 1981), and equally rare transcripts have been detected in CNS tissue (Brilliant et al., 1984). The role of this very rare mRNA class and whether the mRNAs are translated remains to be determined. In addition, the frequency of transcript data from whole brain could be misleading because the extreme cellular heterogeneity in the CNS would tend to reducc the copy number for cach ccll that is actually synthesizing the protein. Finally, it is unlikely that polymorphic differences between individual rats could significantly alter the above data, for the majority of the cell lines were from the BDIX inbred strain, and the average heterozygosity between human fibroblasts is less than $1 \%$ as defined by $2 \mathrm{D}$ gel analysis (McConkcy et al., 1979; Walton et al., 1979).

The second potential problem is the clonal cell lines, for the majority were derived from chemically induced brain tumors. It is possible that transformation and adaptation to cell culture significantly alter protein synthesis in the cells and therefore invalidate the results. This possibility is unlikely for the following reasons: (1) An analysis of cellular proteins from a variety of normal cells and their transformed derivatives by $2 \mathrm{D}$ gel electrophoresis has failed to detect the appearance of any new proteins, or loss of proteins, in the transformed cells (Bravo and Celis, 1980, 1982). Instead of qualitative changes, numerous differences in the relative proportions of polypeptides were observed among the 1300 proteins resolved in the normal and transformed cells. The data presented here have been based solely on the presence or absence of a given protein. Multiple runs of the same sample and several gel exposures were employed to ensure the detection of low-intensity spots. (2) When the extracellular proteins from primary cultures of CNS cells were compared with the extracellular material from the cell lines, essentially all of the proteins from the primary cultures were found among those released from the clonal cell lines $(94 \%$ overlap with B28, which synthesizes almost all of the proteins of the combined cell lines). Although not all of the proteins from the CNS cell lines were found in the 1 primary culture, there are extensive differences in the synthesis of extracellular proteins by glia from different areas of the CNS (unpublished observations). It is therefore possible that only the proteins synthesized by individual glial cells that were shared by the majority of the cells within the population were detected on the gels. (3) Comparison of the extracellular proteins from 2 pairs of tumorigenic and nontumorigenic cells indicates that there are no greater differences between pairs containing transformed cells than between pairs of more normal cells when the total number of extracellular proteins is taken into account (Table 3). (4) Finally, proteins shed from the cell surface are released as a singlemolecular-weight species and are not found in the culture medium as a series of lower molecular weight peptides. This is true for fibroblast proteins (see, for example, McCormick et al., 1979), as well as for surface proteins of nerve and glial cells (RichterLandsberg et al., 1984; Stallcup et al., 1983; Sweadner, 1983). The inclusion of the protease inhibitor Kallikrein in the culture medium had no effect upon the pattern of extracellular protein synthesis (unpublished observations). These experiments rule out the possibility that differences in extracellular proteins between cell types are due to proteolysis.

There is extensive variability in the extracellular proteins synthesized by nerve and glial cell lines from the rat CNS. When the proteins released into the culture medium of clonal nerve and glial cell lines were compared pairwise on 2D acrylamide gels, only about $80 \%$ of the proteins were shared between any 2 cell lines. In contrast to the extracellular proteins, less than $0.2 \%$ of the total cellular proteins varied. These results were similar in nerve and glial cells, indicating that the phenotypic variability within both classes of cells may be similar. Mesodermal cells release fewer proteins into their culture medium, and the variation in extracellular protein between cell types is less. The complexity in total cellular protein synthesis is, however, similar in mesodermal cells and neuroectodermal cells. Since some of the proteins released into the extracellular space are derived from the plasma membrane (Doljanski and Kapellar, 1976; McCormick et al., 1979; Schubert, 1976), there may be extensive specialization of CNS cells at this level. Because the cellular protein complexity is the same between clonal CNS and mesodermal cells, any greater intracellular protein complexity in the CNS must be the result of large numbers of unique phenotypes rather than more protein complexity per cell. Since only quantitative changes in protein synthesis have been detected during the process of nerve differentiation from the neuroblast to a neuron-like cell (Garrels and Schubert, 1979; Schubert et al., 1971), it is unlikely that the examination of more differentiated CNS cells would give results appreciably different from those obtained here with exponentially dividing cells. Finally, these data sugest that the clonal CNS cell lines may serve as both a source for the isolation and characterization of CNSspecific molecules, as well as a convenient assay for nervous system-specific nucleic acid probes.

\section{References}

Arenander, A. T., and J. De Vellis (1981) Glial-released proteins: II. Two-dimensional electrophoretic identification of proteins regulated by hydrocortisone. Brain Res. 224: 105-116.

Axel, R., P. Fcigclson, and G. Schutz (1976) Analysis of the complexity and diversity of mRNA from chick oviduct and liver. Cell 7:247254.

Beckmann, S. L., D. Chikaraishi, S. S. Deeb, and N. Sueoka (1981) Sequence complexity of nuclear and cytoplasmic RNAs from clonal neurotumor cell lines and brain sections of the rat. Biochemistry 20 : 2684-2692.

Bravo, R., and J. E. Celis (1980) Gene expression in normal and virally transformed mouse 3T3B cells. Exp. Cell Res. 127: 249-260.

Bravo, R., and J. E. Celis (1982) Human proteins sensitive to neoplastic transformation in cultured epithelial and fibroblast cells. Clin. Chem. 28: 949-961.

Brilliant, M. H., N. Sueoka, and D. M. Chikaraishi (1984) Cloning of DNA corresponding to rare transcripts of rat brain. Mol. Cell. Biol. 4: $2187-2197$

Brown, I. R., and R. B. Church (1972) Transcription on nonrepeated DNA during mouse and rabbit development. Dev. Biol. 29: 73-81.

Chikaraishi, D. M., M. H. Brilliant, and E. J. Lewis (1983) Cloning and characterization of rat brain-specific transcripts: rare, brain specific transcripts and tyrosine hydroxylase. Cold Spring Harbor Symp. Quant. Biol. 48: 309-318.

Cobert, P., M. Tedeschi, V. Atryzek, and N. Fausto (1977) Diversity 
of polyadenylated mRNA sequences in normal and $12 \mathrm{hr}$ regenerating liver. Dev. Biol. 59: 111-123.

DeVitry, F., R. Picart, C. Jacque, L. Legault, P. Dupouey, and A. TixierVidal (1980) Presumptive common prccursor for ncrve and glial lineages in mouse hypothalamus. Proc. Natl. Acad. Sci. USA 77: 4165-4169.

Doljanski, F., and M. Kapellar (1976) Cell surface shedding-the phenomenon and its possible significance. J. Theor. Biol. 62: 253-260.

Duncan, R., and E. H. McConkey (1982) How many proteins are there in a typical mammalian cell? Clin. Chem. 28: 749-755.

Garrels, J. I. (1979) Two dimensional gel electrophoresis and computer analysis of proteins synthesized by clonal cell lines. J. Biol. Chem. 254: 7961-7977.

Garrels, J. I., and D. Schubert (1979) Modulation of protein synthesis by NGF. J. Biol. Chem. 254: 7970-7985.

Garrels, J. I., J. T. Farrar, and C. Burwell (1984) The quest system for computer analyzed two dimensional electrophoresis of proteins. In Two Dimensional Gel Electrophoresis of Proteins, J. E. Cellis and R. Bravo, eds., pp. 37-91, Academic, New York.

Hagiwara, S., and S. Miyazaki (1977) $\mathrm{Ca}$ and Na spikes in egg cell membrane. In Cellular Neurobiology, Vol. 5, Z. Hall, R. Kelly, and C. F. Fox, eds., pp. 147-158. Liss, New York.

Hahn, W. E., and C. D. Laird (1971) Transcription of nonrepetitive DNA in mouse brain. Science 173: 158-161.

Hastie, N. D., and J. O. Bishop (1976) The expression of three abundance classes of mRNA in mouse tissues. Cell 9: 761-774.

Kimes, B. W., and B. L. Brandt (1976) Characterization of two putative smooth muscle cell lines from rat thoracic aorta. Exp. Cell Res. 98. 949-966.

Laskey, R. A., and A. B. Mills (1975) Quantitative detection of ${ }^{3} \mathrm{H}$ and ${ }^{14} \mathrm{C}$ in polyacrylamide gels by fluorography. Eur. J. Biochem. 56 . 335-341.

Mason, R. M., J. H. Kimura, and V. C. Hascall (1982) Biosynthesis of hyaluronic acid in cultures on chondrocytes from the swarm rat chondrosarcoma. J. Biol. Chem. 257: 2236-2245.

McConkey, E. H., B. J. Taylor, and D. Phan (1979) Human heterozygosity, a new estimate. Proc. Natl. Acad. Sci. USA 76: 6500-6504.

McCormick, P. J., B. J. Keys, C. Pucci, and T. J. Millis (1979) Human fibroblast-conditioned medium contains a $100 \mathrm{k}$ glucose-regulated cell surface protein. Cell 18: 173-182.

Nevo, Z., and A. Dorfman (1972) Stimulation of chondromucoprotein synthesis in chondrocytes by extracellular chondromucoprotein. Proc. Natl. Acad. Sci. UTSA 69: 2069-2072.

O'Farrell, P. H. (1975) High resolution two dimensional electrophoresis of proteins. J. Biol. Chem. 250: 4007-4021.
Richter-Landsberg, C., C. Lee, S. Salton, M. Shelanski, and L. Greene (1984) Release of the NILE and other glycoproteins from cultured PC1 2 rat pheochromocytoma cells and sympathetic neurons. J. Neurochem. 43: 841-848.

Schubert, D. (1976) Proteins secreted by clonal cell lines. Exp. Cell Res. 102: 329-340.

Schubert, D., and M. LaCorbiere (1980) Altered collagen and glycosaminoglycan secretion by a skeletal muscle myoblast variant. J. Biol. Chem. 255: 11557-11563.

Schubert, D., S. Humphreys, F. DeVitry, and F. Jacob (1971) Induced differentiation of a neuroblastoma. Dev. Biol. 25: 514-522.

Schubert, D., S. Heineman, W. Carlisle, I. T. Tarikas, B. Kimes, J. Patrick, J. H. Steinbach, W. Culp, and B. L. Brandt (1974) Clonal cell lines from the rat nervous system. Nature 249: 224-227.

Spitzer, N. C. (1979) Ion channels in development. Annu. Rev. Neurosci. 2: 363-397.

Stallcup, W. B. (1981) The NG-2 antigen, a putative lineage marker. Dev. Biol. 83: 154-165.

Stallcup, W. B., and M. Cohn (1976) Correlation of surface antigens and cell type in cloned cell lines from the rat nervous system. Exp. Cell. Res. 98: 285-297.

Stallcup, W. B., L. S. Arner, and J. M. Levine (1983) An antiserum against the $\mathrm{PC} 12$ cell line defines cell surface antigens specific for neurons and Schwann cells. J. Neurosci. 3: 53-68.

Sweadner, K. (1983) Post-translational modification and evoked release of two large surface proteins of sympathetic neurons. J. Neurosci. 3: 2504-2517.

Tomozawa, Y., and N. Sueoka (1978) In vitro segregation of different cell lines with neuronal and glial properties from a stem cell line RT4. Proc. Natl. Acad. Sci. USA 75: 6305-6309.

Truding, R., M. L. Shelanski, and P. Morell (1975) Glycoproteins released into the culture medium of differentiating neuroblastoma cells. J. Biol. Chem. 250: 9348-9354.

Walton, K. E., D. Styer, and E. I. Gruenstein (1979) Genetic polymorphism in normal human fibroblasts as analyzed by two dimensional polyacrylamide gel electrophoresis. J. Biol. Chem. 254: 79517960.

Wilson, S., E. Baetge, and W. B. Stallcup (1981) Antisera specific for cell lines with mixed nerve and glial properties. Dev. Biol. 83: 146153.

Yaffe, D. (1968) Retention of differentiation potentialities during prolonged cultivation of myogenic cells. Proc. Natl. Acad. Sci. USA 61: $477-483$ 